\title{
EDITORIAL
}

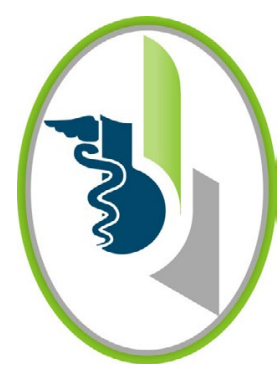

\section{ENSEÑAR A INVESTIGAR EN LAS INSTITUCIONES DE EDUCACIÓN SUPERIOR}

La investigación, como fuente de conocimiento, constituye uno de los principales factores que conducen al desarrollo integral de la sociedad. Las Instituciones de Educación Superior, por la legitimidad que socialmente se les confiere como unidades productoras y socializadoras de saberes, están llamadas a impulsar la investigación como una de sus funciones misionales junto con la docencia y la extensión (1). Para lograrlo, deben enfocar sus esfuerzos hacia la creación de una cultura investigativa, que induzca a docentes y alumnos a pensar, que estimule la duda y la capacidad de observación del individuo, y que lleve a los estudiantes, desde el pregrado, a adquirir las competencias necesarias para llevar a cabo investigación de calidad. Debe considerarse que no solamente se aprende a investigar escribiendo proyectos, también se aprende conociendo el origen de la investigación y entendiendo la importancia de su epistemología como tema obligado antes de empezar la formación en este campo (2).

Lograrlo no es tarea fácil en nuestro medio, pues desde el punto de vista pedagógico, la investigación formativa en el nivel de pregrado se enfrenta con los inconvenientes originados en que las Instituciones de Educación Superior tradicionalmente han sido concebidas para la profesionalización, y no como instituciones para el desarrollo investigativo. También se presenta el problema de la didáctica de la investigación, con las dificultades que conlleva el proceso de formar jóvenes investigadores en la universidad, cuando usualmente no se cuenta con docentes con experiencia en el área que asuman el reto de educar nuevas generaciones que continúen una trayectoria académica-científica. De modo que, para superar la distancia entre ciencia y formación, es necesario el desarrollo de una docencia que proponga la investigación dentro del aula como estrategia de enseñanza y de producción de conocimiento (3). En este sentido, se deben crear programas prácticos de entrenamiento en investigación que permitan aprender haciendo y no solo obtener un cúmulo de conceptos teóricos cuya aplicabilidad muchas veces no es comprendida por el estudiante que apenas se inicia en la práctica del método científico.

La intervención en el proceso de enseñanza de la investigación es fundamental. Se ha propuesto que se realice bajo el enfoque constructivista, tomando en consideración la forma de aprender de los estudiantes de hoy y los factores que intervienen en ello. Dicho enfoque debe comenzar desde el mismo inicio de la formación y debe mantenerse durante todo el proceso hasta culminar con la publicación, oral o escrita, de los resultados. El estudiante debe ser acompañado desde el momento en que surge la idea a investigar; teniendo desde el inicio propósitos claros y una audiencia real a quien se dirigirá la presentación de sus resultados.

Siendo constructiva, la investigación debe ser significativa para los estudiantes, lo que implica que la perciban como una actividad que tiene sentido para ellos, porque les gusta, quieren hacerla y tienen las herramientas cognoscitivas y comunicativas para lograrla (4). Para ello se requiere el compromiso y la participación de todos los estamentos de la educación superior, pero sobre todo la vinculación de docentes amantes de la ciencia, que con su empeño y dedicación hagan germinar la semilla de la investigación en sus estudiantes. El gran reto es lograrlo.

Inés Benedetti Padrón

MD., $\mathrm{PhD}$

Profesora

Facultad de Medicina

Universidad de Cartagena

\section{REFERENCIAS BIBLIOGRÁFICAS}

1. Céspedes, J. C., \& Jiménez, A. C. (2011). Reflexiones acerca de los desafíos en la formación de competencias para la investigación en educación Superior. Actualidades Investigativas En Educación, 9(2).

2. La investigación formativa en estudiantes de pregrado de medicina: análisis de la propuesta pedagógica para la formación de investigadores, CA Castro Moreno - 2014 - repository.usergioarboleda.edu.co

3. Rojas-Betancur, M., \& Méndez-Villamizar, R. (2013). Cómo enseñar a investigar: Un reto para la pedagogía universitaria. Educación y Educadores, 16(1), 95-108

4. Morales, O. A., García, A. G. R., \& Romero, J. T. (2005). Cómo enseñar a investigar en la universidad. Educere, Foro Universitario, Universidad de los Andes. 